\title{
Directionally solidified Ni doped MgO-MgSZ eutectic composites for thermophotovoltaic devices
}

\author{
D. Sola ${ }^{1}$, P.B. Oliete ${ }^{*}$, R.I. Merino, J.I. Peña \\ Instituto de Ciencia de Materiales de Aragón, Universidad de Zaragoza-CSIC \\ 50.018 Zaragoza, Spain \\ * Corresponding author: P. B. Oliete Tel: +34 876555 605; Fax: +34 976761957 \\ E-mail addresses: daniel.sola@um.es (D. Sola); poliete@unizar.es (P.B. Oliete); \\ rmerino@unizar.es (R.I. Merino); jipena@unizar.es (J.I. Peña)
}

${ }^{1}$ Present address: Laboratorio de Óptica, Centro de Investigación en Óptica y Nanofísica Universidad de Murcia, Campus Espinardo

30.100 Murcia, Spain

\begin{abstract}
$\mathrm{Ni}$-doped $\mathrm{MgO}-\mathrm{MgSZ}$ eutectic composites were investigated as selective emitters for thermophotovoltaic devices. MgO-MgSZ:Ni eutectic rods were directionally solidified at 25 and $500 \mathrm{~mm} / \mathrm{h}$ using the laser floating zone technique. Microstructure was strongly dependent on the growth rate, the size of the eutectic phases decreased as the growth rate increased. A hardness of $\sim 11 \mathrm{GPa}$ and a fracture toughness of $\sim 1.6 \mathrm{MPa}$ were obtained from indentation techniques, not showing dependence on the growth rate. Flexure strength increased from $\sim 400 \mathrm{MPa}$ in samples grown at $25 \mathrm{~mm} / \mathrm{h}$ up to $\sim 1 \mathrm{GPa}$ for those
\end{abstract}


solidified at $500 \mathrm{~mm} / \mathrm{h}$, which was attributed to the decrease of the phase size. Thermal emission of eutectic composites was studied up to $1400^{\circ} \mathrm{C}$. An intense broad emission band centred in $1.5 \mu \mathrm{m}$ matching with the sensitive region of the GaSb photoconverter was found. The selective emission was ascribed to the de-excitation of the thermally excited $\mathrm{Ni}^{2+}$ ions.

Keywords: $\mathrm{MgO} / \mathrm{ZrO}_{2}$; Directionally solidified eutectic ceramics; nickel doped selective emitters; mechanical properties; Thermophotovoltaic

\section{INTRODUCTION}

Thermophotovoltaic (TPV) systems convert the electromagnetic radiation emitted by a material at high temperature into electricity. The emission of the hot body (emitter) excites a semiconductor device producing electricity via the photovoltaic effect [1]. In order to increase the efficiency of the TPV conversion, a spectral matching of the thermal emission and the bandgap of the photovoltaic cell should be achieved. In the case of blackbody emitters, although the emission peak can be fitted to the active region of the cell by adjusting the temperature, the broad and continuous emission spectrum produces large amount of non-convertible energy in the long wavelength infrared spectral range. The use of selective emitters radiating in the spectral region of 1-2 microns where photovoltaic cells have the maximum spectral response would minimize the losses in energy $[2,3]$. The control of the spectral output of the emitter can be achieved by using ceramic oxides containing optical ions with electronic transitions that match with the semiconductor gap [4-6]. Photonic crystals, with periodic structures that suppress the 
emissivity of the material in a specific spectral range, have also been investigated as selective emitters [7-9].

Directionally Solidified Eutectic (DSE) ceramics are particularly interesting for TPV devices due to their outstanding mechanical properties, microstructure stability, and corrosion resistance up to temperatures very close to their melting point [10], which make them suitable for the extreme conditions of operation of the TPV converters. Recently, the incorporation of rare-earth ions to $\mathrm{Al}_{2} \mathrm{O}_{3}$-based eutectics [11-14] has allowed obtaining selective emitters fulfilling the TPV requirements. The main disadvantage of the use of rare-earth ion selective emitters is that their thermal emissions consist of very narrow bands corresponding to the $4 \mathrm{f}$ electronic transitions, which results in low power densities unless very high temperatures are used. Different investigations have been addressed to obtain broader thermal emissions in the spectral range where they can be converted into energy by photovoltaic cells to obtain higher efficiencies in the TPV device. Some authors have studied doping with multiple rare-earth ions to extend the emission band by superposing the different rare-earth contributions [15]. Other works have explored selective emitters based on transition metal ions. Transition metal ions have electrons in $3 \mathrm{~d}$ orbitals unshielded by outer shells, which make electronic transitions strongly sensitive to the ion surrounding. Strong coupling to the lattice produces that the emission of transition metal ions consists of broad bands rather than the sharp lines associated to the rare-earth ions. Ferguson et al $[16,17]$ showed that doping $\mathrm{MgO}$ with $3 \mathrm{~d}$ ions such as nickel or cobalt in low concentrations $\left(2-4 \mathrm{wt} \% \mathrm{Co}_{3} \mathrm{O}_{4}\right.$ or $\left.\mathrm{NiO}\right)$ produced strong selective emission matching with GaSb photovoltaic cells. 
The aim of this work is to investigate $\mathrm{MgO}-\mathrm{MgSZ}$ eutectic composites doped with $\mathrm{Ni}^{2+}$ ions as selective emitters for TPV devices. Directionally solidified MgO-MgSZ eutectic rods were fabricated by means of the Laser Floating Zone (LFZ) technique. Among the different directional solidification procedures to grow ceramic oxides from the melt [10], those based on floating zone appear as excellent methods, as the large thermal gradients at the liquid/solid interface achieved with this method allow high growth rates to be used [18]. Hence, the control of the crystal microstructure is possible by means of solidification rates; in particular very fine microstructures or even glasses can be achieved by using high growth rates [19]. In this work, samples were processed using processing rates of $25 \mathrm{~mm} / \mathrm{h}$ and $500 \mathrm{~mm} / \mathrm{h}$ in order to obtain different microstructures. Microstructure, mechanical properties and thermal emission were studied as a function of the solidification rate.

\section{MATERIALS AND METHODS}

Eutectic rods of $\mathrm{MgO}-\mathrm{MgSZ}$ and $\mathrm{Ni}$ doped $\mathrm{MgO}-\mathrm{MgSZ}$ were obtained by directional solidification with the LFZ method. Ceramic powders were prepared using a mixture of commercial powders of $\mathrm{MgO}$ (Aldrich, 99.9\%) and $\mathrm{ZrO}_{2}$ (Aldrich 99\%) with the reported eutectic composition $\left(53 \% \mathrm{~mol} \mathrm{MgO} ; 47 \% \mathrm{~mol} \mathrm{ZrO}_{2}\right)$ [20]. To prepare Ni doped $\mathrm{MgO}-$ $\mathrm{MgSZ}$ rods, $2 \%$ mole extra of $\mathrm{NiO}$ (Alfa Aesar 99.7\%) was added to the eutectic composition. Cylindrical precursors were fabricated isostatically pressing the powder for 3 min at $200 \mathrm{MPa}$ and sintered sintering at $1500{ }^{\circ} \mathrm{C}$ during 12 hours.

Eutectic rods were directionally solidified in air using a continuous wave $\mathrm{CO}_{2}$ laser as a heating source. To eliminate the precursor porosity, different densification stages were 
applied at a low pulling rate $(100-250 \mathrm{~mm} / \mathrm{h})$. The final directional solidification was always performed with the grown crystal travelling downwards to obtain bubble-free samples. Rods were grown at 25 and $500 \mathrm{~mm} / \mathrm{h}$ under two different rotation conditions; counter rotating the solidified rod and the polycrystalline precursor at $50 \mathrm{rpm}$ and without rotation. The solidified rods had a final diameter in the range $1-2.5 \mathrm{~mm}$.

Microstructural characterization was performed in polished transverse and longitudinal cross sections of rods by means of back-scattered electron images obtained in a Scanning Electron Microscope (SEM) (model 6400, Jeol, Tokyo, Japan) or in a Field Emission SEM (FESEM, model Carl Zeiss MERLIN). Specimens for this characterization were prepared using conventional metallographic methods. Semiquantitative compositional characterization was carried out by means of the Energy-dispersive X-ray spectroscopy (EDS) detector coupled to the FESEM. For more precise determination of Ni dopant content, single crystal $\mathrm{MgO}$ and metallic $\mathrm{Ni}$ and $\mathrm{Zr}$ pieces were used as calibration standards.

The Vickers hardness on transverse cross sections was measured following the ASTM C1327-99 Standard using a microhardness tester Matsuzawa, MXT 70, with an indentation load of $4.9 \mathrm{~N}$ and a holding time of $15 \mathrm{~s}$. At least ten valid indentations were made on polished cross sections. The fracture toughness was determined by the indentation technique. The crack lengths were measured using the optical microscope of the microhardness tester.

The bending strength of the eutectics at room temperature was determined in asgrown rods with $1 \mathrm{~mm}$ in diameter with no surface preparation from three-point flexural tests performed in air in an Instron testing machine (model 5565) with a $10 \mathrm{~mm}$ loading 
span and a crosshead speed of $30 \mu \mathrm{m} / \mathrm{min}$. A minimum of five tests was performed on each test condition. All tested samples showed linear load-displacement behaviour and so the strength was calculated from the maximum load in the test using the standard beam theory.

Thermal emission spectra were measured on the as-grown rods with $2.5 \mathrm{~mm}$ in diameter by heating the samples with the $\mathrm{CO}_{2}$-laser focused annularly on the sample surface. Emitted light was collected using an optical fibre and the emission spectrum was measured in the 900-2500 $\mathrm{nm}$ range using an NIR 256-2.5 spectrophotometer from Ocean Optics. The spectral sensitivity of the spectrometer was calibrated using a halogen lamp with the brightness temperature of $2968 \mathrm{~K}$. Temperature of the samples was measured using a two-colour pyrometer (Impac, ISR12-LO MB33) and varied from $1000^{\circ} \mathrm{C}$ to $1500^{\circ} \mathrm{C}$ by changing the laser power.

Hemispherical total reflectance measurements on rods of LFZ processed samples were made with a $110 \mathrm{~mm}$ diameter integrating sphere (Internal DRA2500 accessory) coupled to a CARY 5000 UV-Vis-NIR spectrophotometer. Optical absorption of a Ni doped MgO single crystal was measured with the same CARY5000 spectrophotometer. The crystal was provided by Prof. V. M. Orera, and had been solidified by the arc fusion method at Oak Ridge National Laboratory. The amount of Ni dopant in this crystal was $0.23 \pm 0.3$ $\% \mathrm{Ni}$ (cation basis) and was determined by Energy-dispersive X-ray spectroscopy on the FESEM microscope, using single crystal $\mathrm{MgO}$ and metallic $\mathrm{Ni}$ as calibration standards. 


\section{RESULTS AND DISCUSSION}

\subsection{Microstructure}

Eutectic rods of $\mathrm{MgO}-\mathrm{MgSZ}$ and $\mathrm{Ni}$ doped $\mathrm{MgO}-\mathrm{MgSZ}$ were obtained by directional solidification using two different solidification rates in order to achieve different microstructures. Figure 1 shows transverse (a) and longitudinal (b) cross sections of a Ni doped $\mathrm{MgO}-\mathrm{MgSZ}$ eutectic rod grown at $25 \mathrm{~mm} / \mathrm{h}$ with counter rotation. The eutectic microstructure consists of $\mathrm{MgO}$ fibres (dark contrast) embedded in a magnesia stabilized zirconia matrix, MgSZ (light contrast), as shown in Figure 1(c). The content of magnesia in zirconia ( $\sim 23 \% \mathrm{~mol}$ ) was obtained from Energy-dispersive X-ray spectroscopy (EDS). This fibrous microstructure has been previously reported for undoped $\mathrm{MgO}-\mathrm{MgSZ}$ eutectics $[20,21]$. Hence the incorporation of nickel to the composition does not seem to produce changes in the microstructure.

The microstructure was not homogeneous; in addition to the fibrous microstructure, a banding formed by coarsened $\mathrm{MgO}$ and $\mathrm{MgSZ}$ phases was observed in both cross sections (see Figure 1(a) and (b)). The presence of banding has been previously ascribed to instabilities in the melt produced by periodic perturbations [22]. The bands in the longitudinal section were separated about $7.5 \mu \mathrm{m}$ in length, close to the distance travelled by the rod in a revolution, indicating that the banding phenomenon was related to the rotation speed of the rod during the directional solidification. In order to achieve homogeneous microstructures, eutectic rods were solidified without rotation of crystal and precursor. From now on, all the results presented here will correspond to rods grown under these processing conditions. 

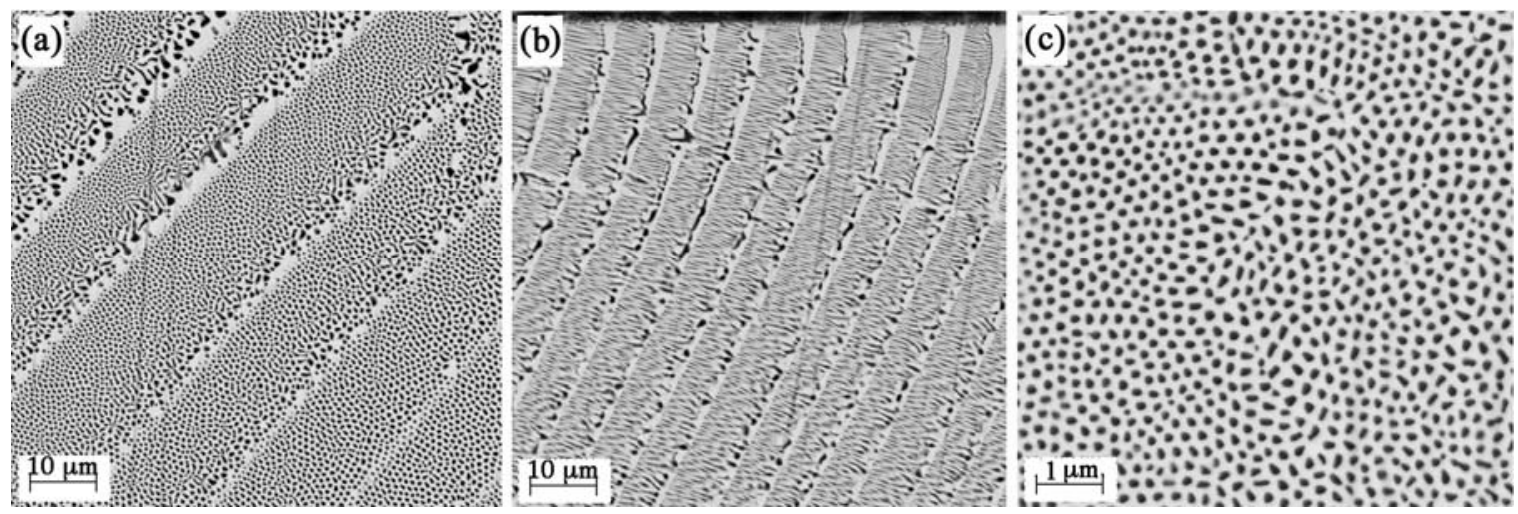

Figure 1: Back-scattered scanning electron micrographs of the (a) transverse and (b) longitudinal cross sections of a Ni doped $\mathrm{MgO}-\mathrm{MgSZ}$ eutectic rod solidified at $25 \mathrm{~mm} / \mathrm{h}$ counter rotating grown rod and polycrystalline precursor at $50 \mathrm{rpm}$. (c) Detail of the eutectic microstructure of the transverse cross section.

Figures 2 and 3 show SEM micrographs corresponding to transverse cross sections of $\mathrm{MgO}-\mathrm{MgSZ}$ and Ni doped $\mathrm{MgO}-\mathrm{MgSZ}$ eutectic rods with $1 \mathrm{~mm}$ in diameter grown at 25 $\mathrm{mm} / \mathrm{h}$ and $500 \mathrm{~mm} / \mathrm{h}$. As expected for growth without rotation, banding was not observed for either of the two processing rates.

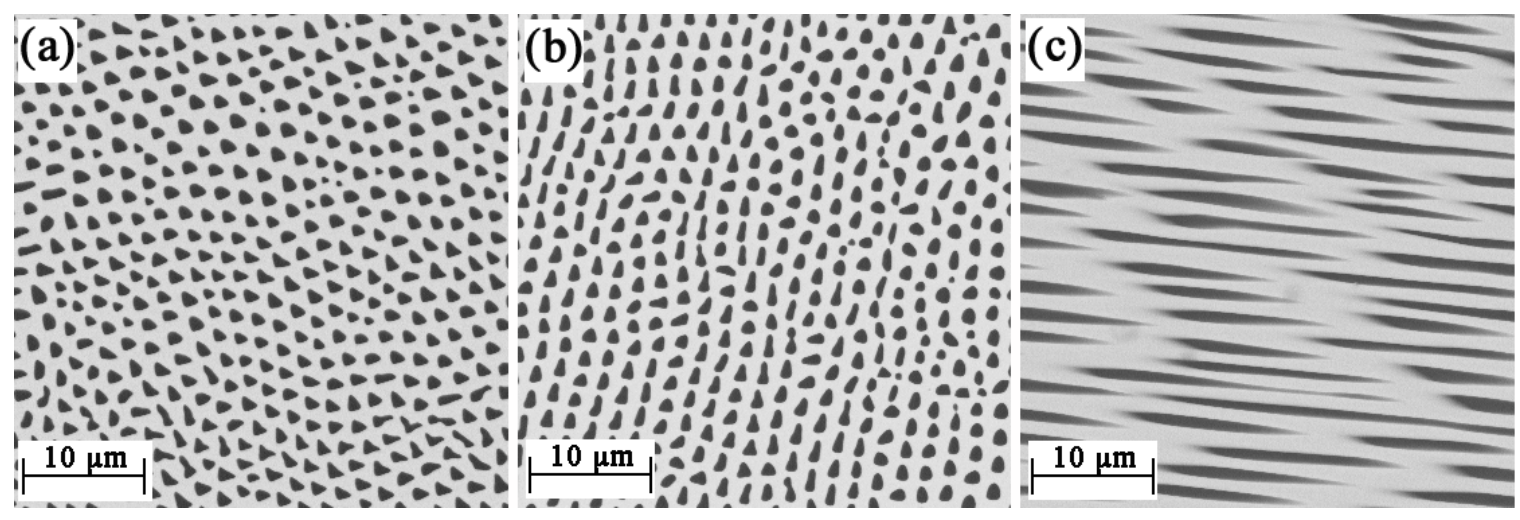

Figure 2: Back-scattered scanning electron micrographs of the transverse cross section of

(a) $\mathrm{MgO}-\mathrm{MgSZ}$ and (b) Ni doped $\mathrm{MgO}-\mathrm{MgSZ}$ and (c) longitudinal cross-section of $\mathrm{Ni}$ doped $\mathrm{MgO}-\mathrm{MgSZ}$ eutectic rods solidified at $25 \mathrm{~mm} / \mathrm{h}$ without rotation.

doi published manuscript: $\underline{10.1016 / \text { j.jeurceramsoc.2018.12.032 }}$

(C) 2018 This manuscript version is made available under the CC-BY-NC-ND 4.0 license http://creativecommons.org/licenses/by-nc-nd/4.0/ 
In the case of the rods grown at $25 \mathrm{~mm} / \mathrm{h}$ (Figure 2) the microstructure was found to be homogeneous throughout the cross section. The microstructure was very similar in both $\mathrm{MgO}-\mathrm{MgSZ}$ and Ni doped $\mathrm{MgO}-\mathrm{MgSZ}$ eutectics and it consisted of $\mathrm{MgO}$ fibres of $1 \mu \mathrm{m}$ in diameter parallel to the growth direction and embedded in a MgSZ matrix. Fibres of $\mathrm{MgO}$ presented frequently a roughly triangular shape rather than a circular section. It should be noted that the $\mathrm{MgO}$ growth direction in this eutectic is the $<111>$ ternary axis [20], which could explain the characteristic triangular shape observed in the fibres. The volume fractions of the $\mathrm{MgO}$ phase, estimated from the area fraction in SEM micrographs were found to be $28.1 \pm 0.6$ and $29.5 \pm 0.1 \%$ for $\mathrm{MgO}-\mathrm{MgSZ}$ and $\mathrm{Ni}$ doped $\mathrm{MgO}-\mathrm{MgSZ}$ eutectic rods, respectively. Eutectic interspacing, $\lambda$, was obtained in both samples by linear interception methods using SEM images corresponding to transverse cross sections (see Table 1$)$. A very similar $\lambda$-value $(\sim 2 \mu \mathrm{m})$ was found for both undoped and Ni doped eutectics.

The use of higher solidification rates led to a non-planar growth and the formation of colonies. Figure 3 shows micrographs of transverse cross sections of $\mathrm{MgO}-\mathrm{MgSZ}$ and $\mathrm{Ni}$ doped $\mathrm{MgO}-\mathrm{MgSZ}$ eutectic rods grown at $500 \mathrm{~mm} / \mathrm{h}$. The microstructure in the centre of the rod did not show significant differences with the nickel content, as shown in Figures 3(a1) and 3(b1). For both samples, it consisted of colonies roughly equiaxial in the transverse cross-section with a diameter about 30-35 $\mu \mathrm{m}$ and elongated along the growth direction. The colonies presented a boundary of 6-8 $\mu \mathrm{m}$ in thickness formed by coarsened $\mathrm{MgO}$ and $\mathrm{MgSZ}$ phases. Inside the colony, the eutectic microstructure consisted of a mixing of a fine lamellar and fibrous microstructure with a eutectic interspacing, $\lambda$, much 
lower than the obtained in samples solidified at $25 \mathrm{~mm} / \mathrm{h}$ (see Table 1). The decrease of the size of the phases with the growth rate, $v$, was in agreement with the Jackson and Hunt relationship $\lambda \cdot v^{1 / 2}=C$ [23], where $C$ is a constant which depends essentially on the phase diagram and the diffusion coefficient of the ions in the melt. C-values of $5.3 \mu \mathrm{m}^{3 / 2}$. $\mathrm{s}^{1 / 2}$ for pure eutectics and $5.4 \mu \mathrm{m}^{3 / 2} \cdot \mathrm{s}^{1 / 2}$ for nickel doped eutectics were estimated from the interspacing data, lower than the one reported by Kennard [20] for MgO-MgSZ eutectics $\left(\sim 7 \mu \mathrm{m}^{3 / 2} \cdot \mathrm{s}^{/ 1 / 2}\right)$.

Table 1: Eutectic interspacing $(\lambda)$ of $\mathrm{MgO}-\mathrm{MgSZ}$ and $\mathrm{Ni}$ doped $\mathrm{MgO}-\mathrm{MgSZ}$ eutectic rods grown at 25 and $500 \mathrm{~mm} / \mathrm{h}$. (f: fibrous and 1: lamellar microstructure inside colonies; s: surface microstructure). \% $\mathrm{NiO}$ corresponds to the nominal percentage.

\begin{tabular}{l|c|c|c}
\hline \multirow{2}{*}{ Growth rate } & $\% \mathrm{NiO}(\mathrm{mol})$ & $\begin{array}{c}\text { microstructure } \\
\text { pattern }\end{array}$ & $\lambda(\mu \mathrm{m})$ \\
\hline \multirow{2}{*}{$25 \mathrm{~mm} / \mathrm{h}$} & 0 & fibrilar & $2.00 \pm 0.11$ \\
\cline { 2 - 4 } & 2 & fibrilar & $2.04 \pm 0.14$ \\
\hline \multirow{3}{*}{$500 \mathrm{~mm} / \mathrm{h}$} & \multirow{2}{*}{0} & colonies & f: $0.49 \pm 0.04$ \\
\cline { 2 - 4 } & \multirow{2}{*}{2} & (fibrilar in surface) & 1: $0.55 \pm 0.06$ \\
& & s: $0.46 \pm 0.04$ \\
& & (lamellar in surface) & f: $0.58 \pm 0.07$ \\
& & s: $0.54 \pm 0.03$ \\
\hline
\end{tabular}




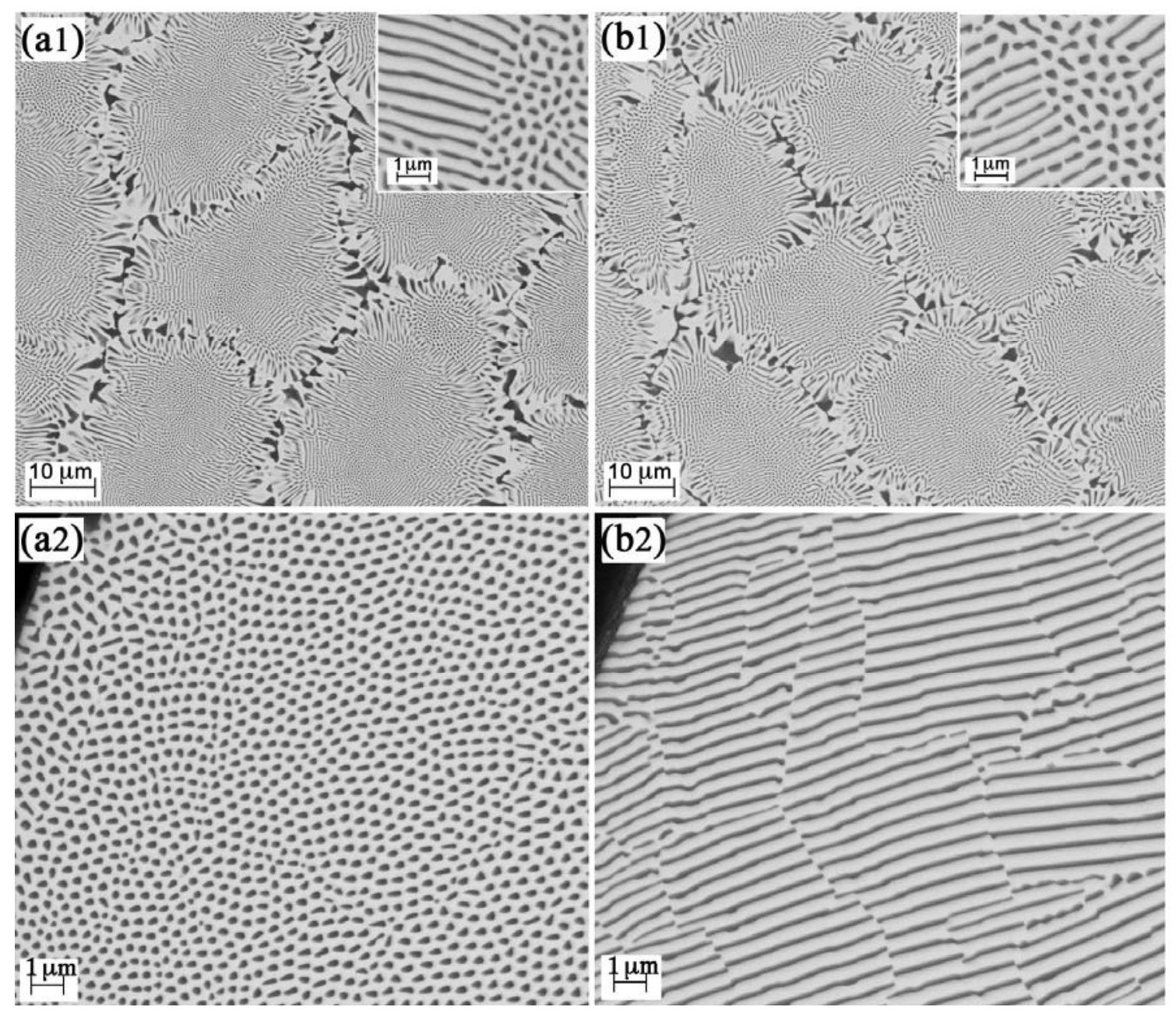

Figure 3: SEM micrographs of the transverse cross section of (a) MgO-MgSZ and (b) Ni doped $\mathrm{MgO}-\mathrm{MgSZ}$ eutectic rods solidified at $500 \mathrm{~mm} / \mathrm{h}$ without rotation. a1/b1 show the microstructure in the centre of the rod, a2/b2 near the surface. Insets show the microstructure inside the colonies.

Near the surface (in a thickness ranging 100-200 $\mu \mathrm{m}$ ), no colonies were observed and microstructure was dependent on the nickel content, Figures 3(a2) and 3(b2). Ni-free samples presented a fibrous microstructure as in the case of the rods grown at $25 \mathrm{~mm} / \mathrm{h}$. However, a lamellar microstructure was found in nickel doped eutectic rods. Table 1 shows a summary of the microstructure geometry and eutectic interspacing for both 
eutectics (pure and Ni-doped) solidified at 25 and $500 \mathrm{~mm} / \mathrm{h}$ obtained in samples with 1 $\mathrm{mm}$ in diameter. It is worth noting that fibrous geometries are favoured in eutectics in which the minority phase presents a volume fraction less than $28 \%$ [10] and the volume fraction of $\mathrm{MgO}$ in this eutectic is nearby the boundary between lamellar and fibrous geometries. So, very small changes in the solidification process could produce the transition from a rod to lamellar microstructure. Echigoya [24] observed in MgO-MgSZ eutectics solidified using Bridgman technique areas with fibrous microstructure and other regions in the same sample showing a lamellar geometry. We have also observed here some variations in the morphology of the microstructure of Ni doped $\mathrm{MgO}-\mathrm{MgSZ}$ eutectics in rods grown with the largest diameter $(2.5 \mathrm{~mm})$.

The nickel content in the Ni-doped eutectic rods after laser processing was estimated from EDS. The dopant was mainly found in the $\mathrm{MgO}$ phase independently of the growth rate, from the analysis of coarse particles in intercolony regions. In the case of the rod grown at $25 \mathrm{~mm} / \mathrm{h}$ a content of nickel close to detection limit $(0.1 \% \mathrm{~mol} \mathrm{NiO})$ was obtained, much lower than the nominal content $(2 \% \mathrm{~mol} \mathrm{NiO})$. Rods processed at 500 $\mathrm{mm} / \mathrm{h}$ presented a nickel composition $(0.5-0.6 \% \mathrm{NiO})$ significantly higher. The different content of nickel in the rods solidified at $500 \mathrm{~mm} / \mathrm{h}$ and $25 \mathrm{~mm} / \mathrm{h}$ was attributed to a higher evaporation of the nickel when the directional solidification is carried out at lower solidification rates. This assumption is supported by our experience in solidifying materials from $\mathrm{NiO}$ containing melts [25], the fact that $\mathrm{NiO}$ has lower melting temperature and larger vapour pressure at $2000 \mathrm{~K}$ than $\mathrm{ZrO}_{2}$ and $\mathrm{MgO}$ [26-27] and it has also been mentioned in the literature of solidification of Ni doped crystals [28]. 


\subsection{Mechanical characterization}

The mechanical properties (hardness, indentation fracture toughness and flexure strength) were measured at room temperature in samples grown at $25 \mathrm{~mm} / \mathrm{h}$ and 500 $\mathrm{mm} / \mathrm{h}$. The average values and corresponding standard errors are presented in Table 2 .

Table 2: Hardness (HV), indentation fracture toughness (IFT) and flexural strength $\left(\sigma_{\mathrm{f}}\right)$ of $\mathrm{MgO}$ $\mathrm{MgSZ}$ and eutectic rods grown at 25 and $500 \mathrm{~mm} / \mathrm{h}$. \%NiO corresponds to the nominal percentage.

\begin{tabular}{l|cccc}
\hline Growth rate & $\% \mathrm{NiO}(\mathrm{mol})$ & $\mathrm{HV}(\mathrm{GPa})$ & $\mathrm{IFT}\left(\mathrm{MPa} \cdot \mathrm{m}^{1 / 2}\right)$ & $\sigma_{\mathrm{f}}(\mathrm{GPa})$ \\
\hline \multirow{2}{*}{$25 \mathrm{~mm} / \mathrm{h}$} & 0 & $10.8 \pm 0.4$ & $1.6 \pm 0.1$ & $0.35 \pm 0.08$ \\
\cline { 2 - 5 } & 2 & $10.9 \pm 0.3$ & $1.6 \pm 0.1$ & $0.45 \pm 0.08$ \\
\hline \multirow{2}{*}{$500 \mathrm{~mm} / \mathrm{h}$} & 0 & $10.9 \pm 0.4$ & $1.5 \pm 0.2$ & $0.94 \pm 0.20$ \\
\cline { 2 - 5 } & 2 & $11.3 \pm 0.3$ & $1.6 \pm 0.3$ & $1.07 \pm 0.20$ \\
\hline
\end{tabular}

Hardness and indentation fracture toughness were obtained from Vickers microhardness tests on polished transverse cross sections. A hardness value around 11 GPa was obtained in undoped eutectic rods for both pulling rates $(10.8 \pm 0.4 \mathrm{GPa}$ for samples grown at $25 \mathrm{~mm} / \mathrm{h}$ and $10.9 \pm 0.4 \mathrm{GPa}$ for those grown at $500 \mathrm{~mm} / \mathrm{h}$ ). This value is between the hardness values reported for both eutectic phases, $\mathrm{MgO}$ (9.2 GPa, Ref [29]) and MgSZ (13.2 GPa, Ref. [30]). Similar values were obtained in nickel-doped eutectics grown at $25 \mathrm{~mm} / \mathrm{h}(10.9 \pm 0.3 \mathrm{GPa})$ whereas a slight increase in hardness was obtained in nickel-doped eutectics solidified at $500 \mathrm{~mm} / \mathrm{h}(11.3 \pm 0.3 \mathrm{GPa})$. It has been reported that the presence of substitutional nickel ions increases the hardness in $\mathrm{MgO}$

doi published manuscript: $\underline{\text { 10.1016/j.jeurceramsoc.2018.12.032 }}$

(c) 2018 This manuscript version is made available under the CC-BY-NC-ND 4.0 license http://creativecommons.org/licenses/by-nc-nd/4.0/ 
single crystals by acting as obstacles for dislocation motion [29], which would explain the higher hardness in the nickel doped sample grown at $500 \mathrm{~mm} / \mathrm{h}$. This effect would not be appreciated in the nickel doped eutectic grown at $25 \mathrm{~mm} / \mathrm{h}$ as the solidification at low rate produced eutectics with a significant reduction of nickel content, explaining the coincident hardness values obtained for doped and undoped samples processed at this rate.

Indentation fracture toughness was determined from the length of the cracks emerging from the Vickers indentation corners. Although the indentation method is not considered appropriate for the absolute determination of fracture toughness [31] it is adequate to compare the values obtained from samples grown with different processing conditions and to provide an estimation of the fracture toughness. The cracks developed from the indentation fulfilled the Niihara condition for median cracks $(c / a>2.5)$ [32] with $c$, the distance from the centre of the indentation to the crack tip and $a$, half diagonal of the Vickers indentation. Table 2 shows the indentation fracture toughness calculated using the equation proposed by Anstis [33] for median cracks,

$$
I F T=0.016(E / H)^{1 / 2}\left(P / c^{3 / 2}\right)
$$

where $P$ is the indentation load, E, the Young modulus of the eutectic and $\mathrm{H}$, the hardness Vickers of the eutectic. An E-value of $285 \mathrm{GPa}$ was taken for all the samples [21]. Figure 4 shows the indentation fracture pattern. Crack propagation was mainly transgranular and crack deflection was hardly observed at the eutectic interfaces. The influence of nickel content and solidification rate on indentation fracture toughness was negligible. The mean value obtained using the indentation method $\left(1.6 \mathrm{MPa} \cdot \mathrm{m}^{1 / 2}\right)$ was 
slightly higher than the fracture toughness reported for $\mathrm{MgO}-\mathrm{MgSZ}$ eutectic rods obtained through tensile tests of notched $\operatorname{rods}\left(1.2 \mathrm{MPa} \cdot \mathrm{m}^{1 / 2},[21]\right)$.

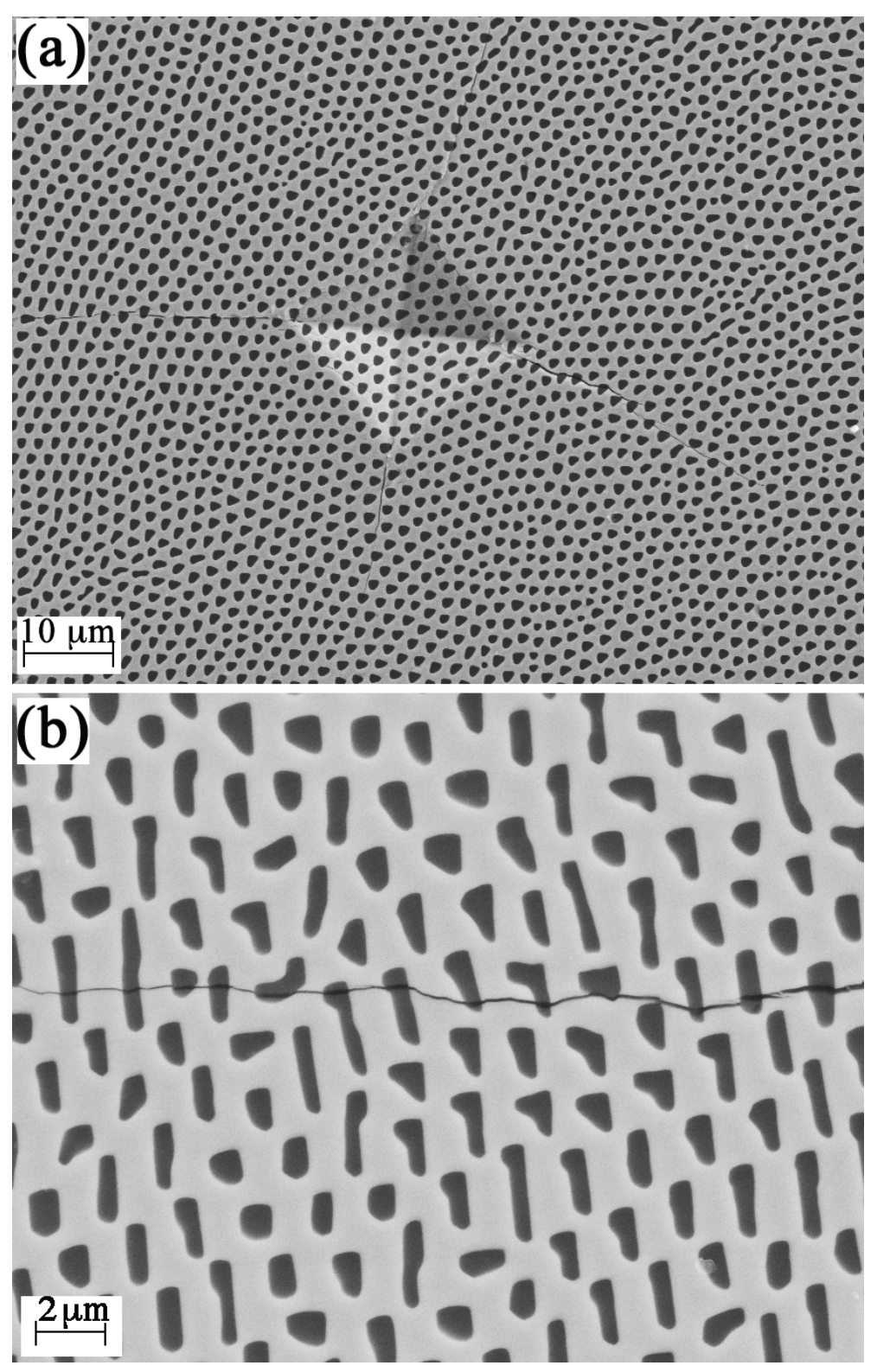

Figure 4: (a) SEM micrograph showing the cracking pattern of Ni doped MgO-MgSZ eutectic rod grown at $25 \mathrm{~mm} / \mathrm{h}$ under an indentation load of $4.9 \mathrm{~N}$. (b) Detail of the crack path of pure $\mathrm{MgO}-\mathrm{MgSZ}$ eutectic rod grown at $25 \mathrm{~mm} / \mathrm{h}$. 
Bending strength was determined at room temperature for all the samples. The flexure strength values are presented in Table 2 . We can observe that the flexure strength does not show a significant dependence with the nickel content but it is strongly affected by the processing rate, increasing from a value of $\sim 400 \mathrm{MPa}$ for samples grown at $25 \mathrm{~mm} / \mathrm{h}$ up to $\sim 1 \mathrm{GPa}$ for those solidified at $500 \mathrm{~mm} / \mathrm{h}$. This dependence can be attributed to the decrease of the phase size when increasing the processing rate. It is worth noting that in brittle ceramics the mechanical strength is controlled by the size of surface defects and the resistance to crack propagation through the relation $\sigma_{f} \propto K_{I C} / \sqrt{ } a_{C}$, with $\sigma_{f}$, the flexural strength, $K_{I C}$, the fracture toughness and $a_{c}$, the critical defect size. As these samples present a similar $K_{I C}$ value, irrespective of the nickel content or the processing rate, the parameter limiting the strength will be the critical defect size, which will be largely dependent on the microstructure. The finer microstructure observed in the samples processed at higher rates will be accompanied by smaller defects and therefore, by a higher flexure strength.

Flexure strength in undoped $\mathrm{ZrO}_{2}-\mathrm{MgO}$ eutectics has been previously reported. Orera et al [21] measured the flexural strength in eutectics solidified at low solidification rates showing a fibrous microstructure with $\mathrm{MgO}$ fibres about $1 \mu \mathrm{m}$ in diameter. The reported value $(300 \mathrm{MPa})$ is similar to the result obtained in this work in samples grown at 25 $\mathrm{mm} / \mathrm{h}$. Kennard et al [20] studied the bending strength of prisms cut from ingots solidified between 20 and $160 \mathrm{~mm} / \mathrm{h}$ with a colony microstructure. Contrary to what was observed in our experiments, bending strength was almost independent on the solidification rate. A low value for $\sigma_{\mathrm{f}} \sim 160 \mathrm{MPa}$ was measured in all the range of solidification rates despite the change in the $\mathrm{MgO}$ fibre size and spacing inside the 
colony. The results were explained considering that the parameter controlling the strength was the colony size $(250 \mu \mathrm{m})$ or, more likely, the size of the colony boundaries $(>50 \mu \mathrm{m})$, essentially constant for all the growth rates. In our case, the microstructure of the rod grown at $25 \mathrm{~mm} / \mathrm{h}$ was fibrillar throughout the cross section whereas the samples solidified at $500 \mathrm{~mm} / \mathrm{h}$ presented colonies (smaller than those reported in Ref. [20]) inside the rod.

We have to take into account that the rod in a bending test is subjected to the maximum tensile stress over only a thin layer on its surface. Therefore, the strengthcontrolling parameter should be the microstructure size of the rods in this surface layer. The rods grown in this work at $500 \mathrm{~mm} / \mathrm{h}$ did not present colonies in the surface for a thickness at least of $100 \mu \mathrm{m}$ and so, the eutectic interspacing nearby the surface should be considered in the analysis of the flexure strength more than the colony boundary size.

\subsection{Thermal emission}

Thermal emission in the near infrared spectral region was measured in nickel doped eutectic rods using a $\mathrm{CO}_{2}$-laser as the heating source for samples grown at 25 (Ni25) and $500 \mathrm{~mm} / \mathrm{h}$ (Ni500-1). To achieve eutectic ceramics with higher nickel content, an extra rod was directionally solidified at $500 \mathrm{~mm} / \mathrm{h}$ without using previous densification stages (Ni500-2), in order to avoid nickel evaporation. After the thermal emission experiments, nickel content was estimated by EDS in the three samples (using $\mathrm{MgO}, \mathrm{Ni}$ and $\mathrm{Zr}$ as quantitative standards).Nickel was detected only in the $\mathrm{MgO}$ phase of the eutectic. The content of nickel obtained in the $\mathrm{MgO}$ phase was $0.35 \% \pm 0.1 \% \mathrm{~mol} \mathrm{NiO}$ in $\mathrm{Ni} 25,1.1 \pm 0.1$ 
$\% \mathrm{~mol} \mathrm{NiO}$ in $\mathrm{Ni} 500-1$, and $5.5 \pm 0.2 \% \mathrm{~mol} \mathrm{NiO}$ in Ni500-2. The amount of $\mathrm{Ni}$ dissolved into the MgSZ phase is, if any, below the detection limit.

Figure 5a shows the emission of Ni-doped MgO-MgSZ eutectic rods Ni500-1, Ni5002 and Ni25. For comparison, the thermal emission for pure $\mathrm{MgO}-\mathrm{MgSZ}$ eutectic grown at $500 \mathrm{~mm} / \mathrm{h}$ is also presented in dotted line. We can observe that the spectra of the samples containing nickel show an intense band centred at $\sim 1460 \mathrm{~nm}\left(6850 \mathrm{~cm}^{-1}\right)$, matching with the active region of GaSb photovoltaic cells. This strong emission was ascribed to the radiative de-excitation of the thermally excited $\mathrm{Ni}^{2+}$ ions. Thermal emission is weaker in Ni doped eutectics solidified at $25 \mathrm{~mm} / \mathrm{h}$, as expected from the lower nickel content in these samples, the highest thermal emission corresponding to the sample with 5.5\%mol $\mathrm{NiO}$. In addition to the intense $\mathrm{Ni}^{2+}$ emission, we can observe a weak broad background, which was attributed to the thermal emission of the eutectic matrix, in agreement with the spectrum measured for the undoped sample. 

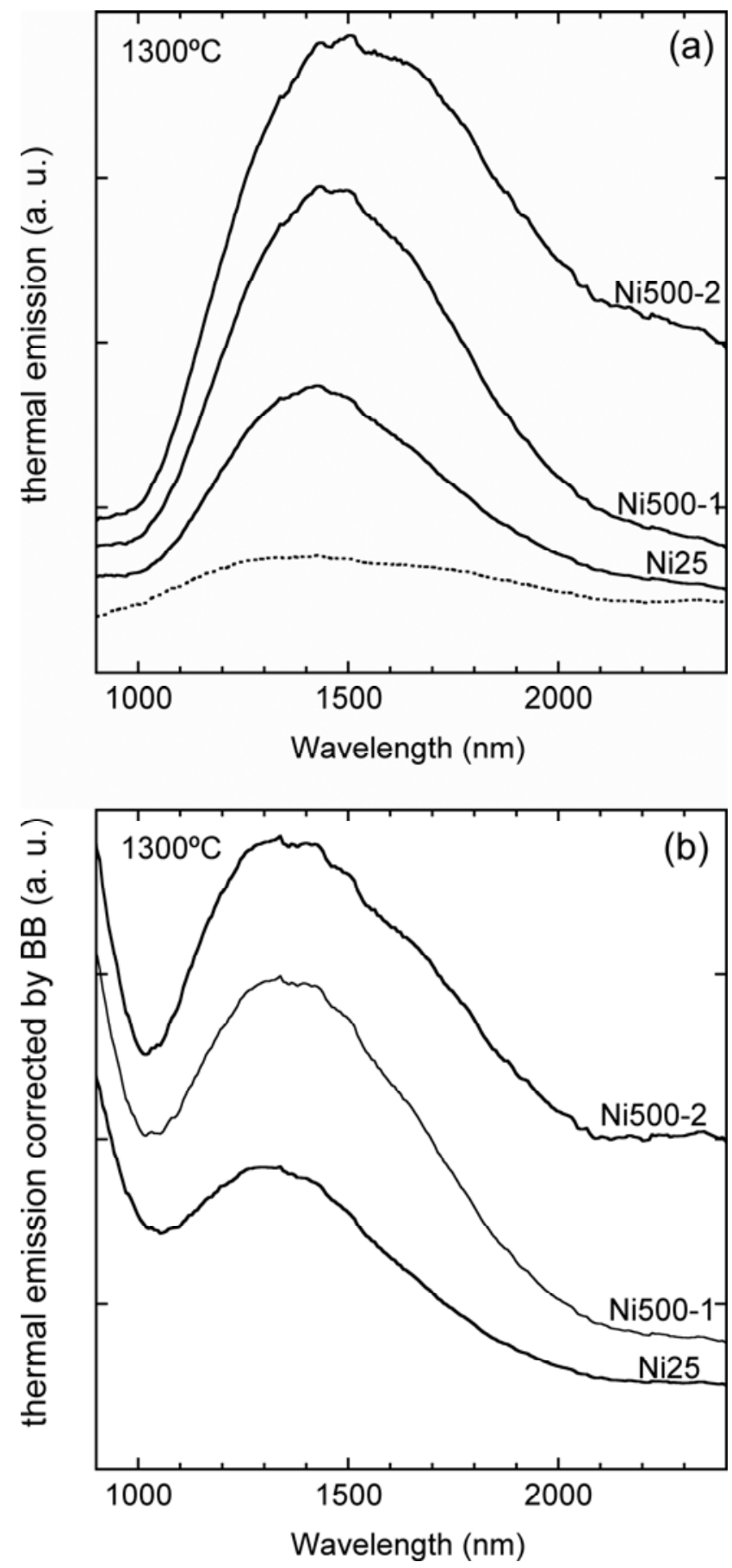

Figure 5: (a) Thermal emission spectra of Ni25, Ni500-1 and Ni500-2 measured at $1300{ }^{\circ} \mathrm{C}$. The dotted line shows the emission measured in an undoped $\mathrm{MgO}-\mathrm{MgSZ}$ eutectic rod grown at $500 \mathrm{~mm} / \mathrm{h}$. (b) Spectra obtained by dividing the thermal emission spectra of Ni25, Ni500-1 and Ni500-2 at $1300{ }^{\circ} \mathrm{C}$ by the Planck profile. 
In order to analyse the features of the nickel emission, such as band position, we have to take into account that thermal emission is modulated by the Planck profile. At the high temperatures of the thermal emission measurements the maximum and the maximumslope wavelengths of the Planck profile lie in the wavelength window used in the experiments. Considering the width of the emission band, this modulation can modify substantially the shape of the near infrared spectra. So, thermal emission divided by the blackbody radiation was used to perform spectroscopical analysis and is shown in Figure 5b. The maxima of the bands after correction were shifted to $\sim 1360 \mathrm{~nm}\left(7350 \mathrm{~cm}^{-1}\right)$. The increase observed towards shorter wavelengths is a consequence of the $\mathrm{Ni}^{2+}$ higher energy electronic transitions

With the aim of obtaining more information about the nickel electronic transitions involved in the thermal emission, the hemispherical total reflectance was measured at room temperature in Ni500-2. Three LFZ rods were fixed side by side on a $10 \times 10 \mathrm{~mm}^{2}$ window, and on the reflectance port of the integrating sphere to register the reflectance. Some light escaped through the spaces between samples (not participating in the experiment), other part was not hitting the sphere after reflectance due to the cylindrical shape of the samples. Therefore, the reflectance spectra were renormalized dividing by the reflectance value measured at the long wavelength side of the spectra $\left(\mathrm{R}_{\text {long }}\right)$. We have estimated emissivity as $\varepsilon \approx 1-\mathrm{R} / \mathrm{R}_{\text {long. }}$. Figure $6 \mathrm{~b}$ shows the estimated emissivity. Note that at room temperature $\varepsilon \approx 0.3$ at the maximum of the NIR band. For comparison, Figure $6 \mathrm{a}$ shows the absorption spectrum of a $\mathrm{MgO}$ single crystal doped with $0.23 \pm 0.03 \mathrm{~mol} \%$ NiO. The similarity of both curves proves that nickel ions $\left(3 \mathrm{~d}^{8}\right)$ are mainly found in the $\mathrm{MgO}$ eutectic phase and enter the lattice substituting the magnesium ions in an octahedral 
symmetry site. The bands in figure 6 are labelled according to the spin-allowed absorption transitions for octahedrally coordinated $\mathrm{Ni}^{2+}$ in $\mathrm{MgO}$ [34]. The thermal emission obtained at high temperature was attributed to the $\mathrm{Ni}^{2+}$ de-excitation from the first excited state $\left({ }^{3} \mathrm{~T}_{2 \mathrm{~g}}\right)$ to the ground state $\left({ }^{3} \mathrm{~A}_{2 \mathrm{~g}}\right)$. At room temperature the centroid of the absorption band is found at $\sim 1165 \mathrm{~nm}\left(8590 \mathrm{~cm}^{-1}\right)$, and will shift to lower energies by approximately half the Stokes Shift, as temperature increases, according to the configurational coordinate displacement model [35]. The Stokes shift at room temperature of this transition in $\mathrm{MgO}: \mathrm{Ni}^{2+}$ amounts to $1050 \mathrm{~cm}^{-1}$ approximately [36] Further red shift at the high temperatures used in the thermal emission experiments is expected following the thermal expansion of the crystal, lengthening of the $\mathrm{Ni}^{2+-} \mathrm{O}^{2-}$ ligand distance, which will make 10Dq cubic crystal field parameter to decrease accordingly.

Figure 7 shows the thermal emission spectra measured in Ni500-1 at several temperatures. We can observe that both contributions to the emission (the one coming from $\mathrm{Ni}^{2+}$ ions and that from the lattice emission) become more intense when the temperature increases. The thermal dependence of the intensity of the nickel band peak roughly followed the Planck's law. The saturation of the thermal emission observed at high temperatures in highly concentrated rare-earth based selective emitters [13,37] was not found in Ni doped eutectics. The nickel emission band broadened and shifted slightly towards lower energies when increasing the temperature, as expected. In fact, Becker and Rau report a red shift in the absorption bands of $\mathrm{NiO}$ with temperature of the same order of magnitude up to $1200{ }^{\circ} \mathrm{C}$ [38]. 


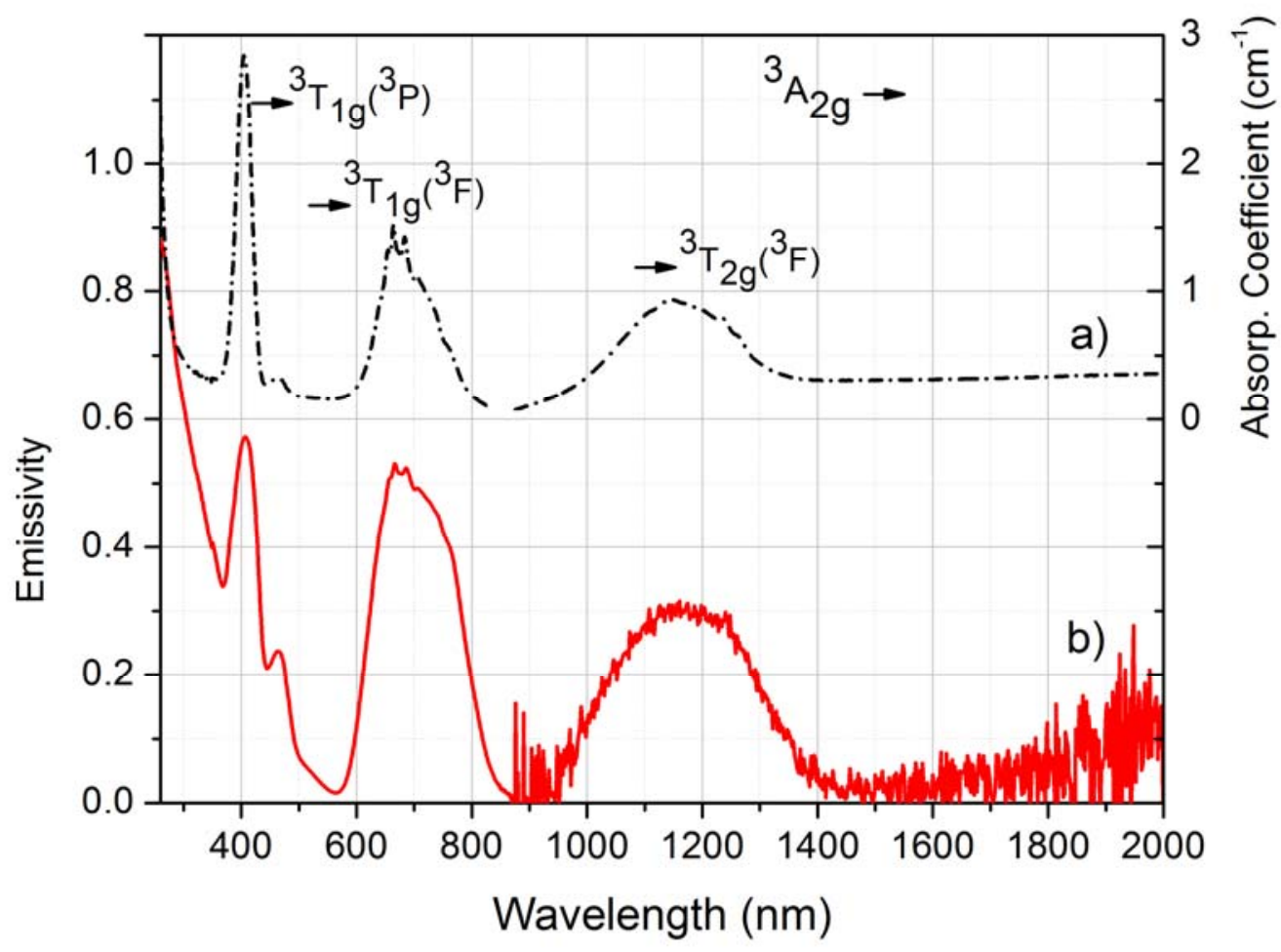

Figure 6: (a) The absorption spectrum of a $\mathrm{Ni}$ doped $\mathrm{MgO}$ single crystal. (b) Emissivity estimated from the hemispherical total reflectance measured on Ni500-2 at room temperature.

In the sample with the highest $\mathrm{Ni}$ content, Ni500-2, a higher contribution to the emission is present in the spectral region of 2-2.4 $\mu \mathrm{m}$, not observed in the Ni25 and Ni500 spectra, which produces a decrease in the emission selectivity (see Figure 5). Ferguson et al [16] reported a similar behaviour for $\mathrm{MgO}$ doped beyond $2 \% \mathrm{~mol} \mathrm{NiO}$, with an increased emissivity at wavelengths between 2 and $6 \mu \mathrm{m}$, ascribed to impurity and dopant interactions. Defects associated to the thermal treatments and bound to the presence of $\mathrm{Ni}$ in the $\mathrm{MgO}$ phase could also generate a background. In the case of Codoped $\mathrm{Al}_{2} \mathrm{O}_{3}$ [39], the selectivity of the $\mathrm{Co}^{2+}$ ions emission was practically missing for a 
doping concentration of $1 \% \mathrm{wt}$, the thermal emission looking more like that of a blackbody emitter.

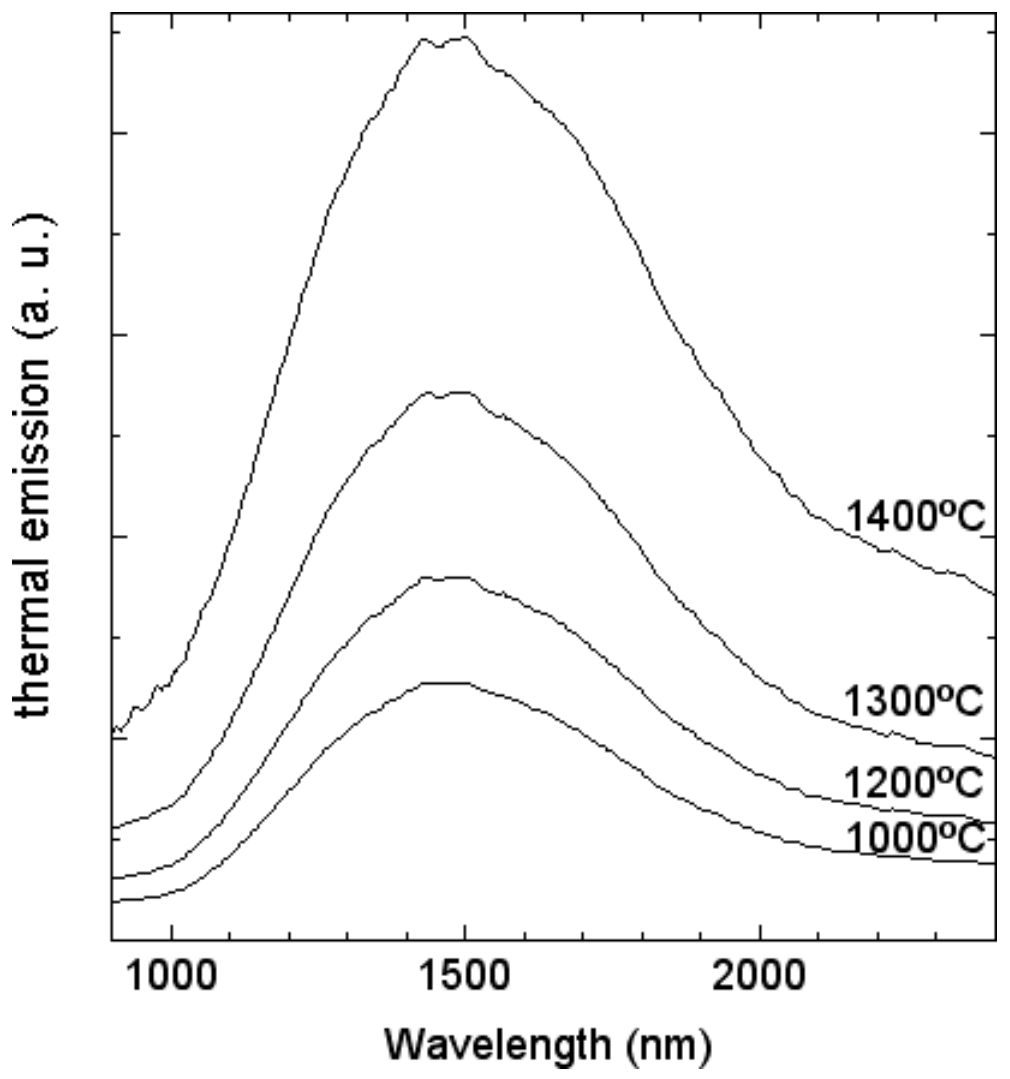

Figure 7: Thermal emission spectra of Ni500-1 at several temperatures.

The host emission was not negligible even at the lowest temperature at which the emission was measured, $1000^{\circ} \mathrm{C}$. Thermal emission in Ni doped $\mathrm{MgO}$ ceramics has been measured [16-17] and a very limited matrix emission was reported, according to the low emissivity of $\mathrm{MgO}$ in this spectral range. Therefore, the significant host contribution observed in $\mathrm{MgO}-\mathrm{MgSZ}$ samples has been ascribed here to the zirconia. Dombrovsky et al. [40] report that the emissivity of a $0.87 \mathrm{~mm}$ thick sample of cubic stabilized zirconia at $2 \mu \mathrm{m}$ increases from very low values at $727^{\circ} \mathrm{C}$ to around 0.27 at $1503^{\circ} \mathrm{C}$, due to the 
contribution of electronic transitions associated to point defects. Ab initio calculations predict an increase of the emissivity of $100 \mu \mathrm{m}$ thick $\mathrm{YSZ}$ at $1727^{\circ} \mathrm{C}$ from 0.3 (defectfree $\mathrm{ZrO}_{2}$ ) up to 0.8 (defective oxide) between 1-2 $\mu \mathrm{m}$ [41]. In the MgSZ eutectic phase, the $\mathrm{Zr}^{4+}$ cation substitution by $\mathrm{Mg}^{2+}$ ions produces a large number of oxygen vacancies in the crystal for charge compensation, which would explain the stronger emission from the matrix observed in these eutectics.

\section{CONCLUSIONS}

$\mathrm{Ni}$ doped $\mathrm{MgO}-\mathrm{MgSZ}$ eutectic rods were directionally solidified by using the Laser Floating Zone technique at growth rates of $25 \mathrm{~mm} / \mathrm{h}$ and $500 \mathrm{~mm} / \mathrm{h}$. Ni dissolves into the $\mathrm{MgO}$ phase. Microstructure was found to be dependent on solidification rate obtaining a homogeneous and fibrous microstructure at low rates and colonies based microstructure at high rates. Eutectic interspacing was strongly dependent on processing rate, decreasing from $2 \mu \mathrm{m}$ down to $0.6 \mu \mathrm{m}$ when increased the growth rate.

Mechanical properties were investigated for both microstructures. The hardness and the fracture toughness did not depend on processing rate whereas the flexural strength increased significantly with increasing the solidification rate due to the microstructure refinement which produced a reduction in the critical defect size. Excellent flexure strength over $1 \mathrm{GPa}$ was obtained for rods grown at $500 \mathrm{~mm} / \mathrm{h}$.

The thermal emission of the Ni-doped MgO-MgSZ eutectic rods consisted of an intense band in the 1-2 $\mu \mathrm{m}$ spectral range, matching GaSb photovoltaic cell sensitive region. The 
selective emission was attributed to the transition from the ${ }^{3} \mathrm{~T}_{2 \mathrm{~g}}$ first excited state to the

${ }^{3} \mathrm{~A}_{2 \mathrm{~g}}$ ground state of the nickel ions in the $\mathrm{MgO}$ lattice. Increasing the nickel content produced an enhancement of the emission intensity but in the samples with the highest doping (5.5 $\mathrm{mol} \% \mathrm{NiO}$ in $\mathrm{MgO}$ ), the selectivity decreased due to the rise of the energy emitted at non-convertible wavelengths $(>1.8 \mu \mathrm{m})$.

Although selective emitters based on nickel doped $\mathrm{MgO}-\mathrm{MgSZ}$ is expected to have a thermostructural performance superior to the $\mathrm{MgO}$ single crystal, the selectivity of the thermal emission should be improved. In order to be used as selective emitters in TPV devices, research in lower emission eutectic hosts and optimization of the dopant content should be addressed.

\section{ACKNOWLEDGEMENTS}

This work has been supported by the Spanish Ministerio de Economía Industria y Competitividad (MINECO) and the CE (FEDER Funds) [grants number MAT201341045-R-EMITEME and MAT-2016-77769R-FLASCERAMAT]. Authors acknowledge the use of Servicio de Microscopia Electrónica (Servicios de Apoyo a la Investigación), Universidad de Zaragoza. The authors also wish to thank Dr. Víctor M. Orera for fruitful discussions and for providing the Ni doped MgO single crystals, and Andrés Almazán for carrying out the bending tests. D. Sola thanks the PIT2 programme of the University of Murcia for the financial support of his contract. 


\section{References}

[1] T.J. Coutts, A review of progress in thermophotovoltaic generation of electricity, Renewable and Sustainable Energy Reviews 3 (1999) 77-184.

[2] A. Licciulli, D. Diso, G. Torsello, S. Tundo, A. Maffezzoli, M. Lomascolo, M. Mazzer, The challenge of high-performance selective emitters for thermophotovoltaic applications, Semicond. Sci. Technol. 18 (2003) S174-S183.

[3] B. Bitnar, W. Durisch, R. Holzner, Thermophotovoltaics on the move to applications, Applied Energy 105 (2013) 430-438.

[4] G.E. Guazzoni, High-Temperature Spectral Emittance of Oxides of Erbium, Samarium, Neodymium and Ytterbium, Appl. Spectr. 26 (1972) 60-65.

[5] D.L. Chubb, A.M.T. Pal, M.O. Patton, P.P. Jenkins, Rare Earth Doped High Temperature Ceramic Selective Emitters, J. Eur. Ceram. Soc. 19 (1999) 2551-2562.

[6] D. Diso, A. Licciulli, A. Bianco, G. Leo, G. Torsello, S. Tundo, A. De Risi, M. Mazzer, Selective emitters for high efficiency TPV conversion: materials preparation and characterisation, AIP Conference. Thermophotovoltaic generation of electricity: 5th Conference. (2003)132-141.

[7] M. Florescu, H. Lee, I. Puscasuc, M. Prallec, L. Florescu, D.Z. Tingb, J.P. Dowling, Improving solar cell efficiency using photonic band-gap materials, Solar energy materials and solar cells 91 (2007) 1599-1610.

[8] H. Sai, T. Kamikawa, Y. Kanamori, K. Hane, H. Yugami, M. Yamaguchi, Thermophotovoltaic Generation with Microstructured Tungsten Selective Emitters, AIP. Conf. Proc., 738 (2004) 206-214. 
[9] X. L. Liu, T. Tyler, T. Starr, A. F. Starr, N. M. Jokerst, W. J. Padilla, Taming the Blackbody with Infrared Metamaterials as Selective Thermal Emitters, Phys. Rev. Lett. 107 (2011) 045901.

[10] J. Llorca, and V.M. Orera, Directionally-solidified eutectic ceramic oxides, Prog. Mater. Sci. 51 (2006) 711-809.

[11] N. Nakagawa, H. Ohtsubo, Y. Waku, H. Yugami, Thermal emission properties of $\mathrm{Al}_{2} \mathrm{O}_{3} / \mathrm{Er}_{3} \mathrm{Al}_{5} \mathrm{O}_{12}$ eutectic ceramics, J. Eur. Ceram. Soc. 25 (2005) 1285-1291.

[12] M.C. Mesa, P.B. Oliete, R.I. Merino, V.M. Orera, Optical absorption and selective thermal emission in directionally solidified $\mathrm{Al}_{2} \mathrm{O}_{3}-\mathrm{Er}_{3} \mathrm{Al}_{5} \mathrm{O}_{12}$ and $\mathrm{Al}_{2} \mathrm{O}_{3}-\mathrm{Er}_{3} \mathrm{Al}_{5} \mathrm{O}_{12}-$ $\mathrm{ZrO}_{2}$ eutectics, J. Eur. Ceram. 33 (2013) 2587-2596.

[13] P.B. Oliete, M.C. Mesa, R.I. Merino, V.M. Orera, Directionally solidified $\mathrm{Al}_{2} \mathrm{O}_{3}$ $\mathrm{Yb}_{3} \mathrm{Al}_{5} \mathrm{O}_{12}$ eutectics for selective emitters, Sol. Energy Mater. Sol. Cells 144 (2016) $405-410$.

[14] D. Sola, P.B. Oliete, J.I. Peña, Directionally solidified fabrication in planar geometry of $\mathrm{Al}_{2} \mathrm{O}_{3}-\mathrm{Er}_{3} \mathrm{Al}_{5} \mathrm{O}_{12}$ eutectic composite for thermophotovoltaic devices, Optics Express, 24 (2016) A823-A831

[15] Z. Chen, P.L. Adair, M.F. Rose, Multiple-dopant selective emitter, Thermophotovoltaic generation of electricity. AIP Conference Proceedings 401 (1997) $181-188$

[16] L.G. Ferguson, F. Dogan, Spectrally selective, matched emitters for thermophotovoltaic energy conversion processed by tape casting, J. Mat. Sc. 36 (2001) 137-146. 
[17] L.G. Ferguson, F. Dogan, Spectral analysis of transition metal-doped MgO "matched emitters" for thermophotovoltaic energy conversion, J. Mat. Sc. 37 (2002) 1301-1308.

[18] F.J. Ester, D. Sola, and J.I. Peña, "Thermal stresses in the $\mathrm{Al}_{2} \mathrm{O}_{3}-\mathrm{ZrO}_{2}\left(\mathrm{Y}_{2} \mathrm{O}_{3}\right)$ eutectic composite during the growth by the laser floating zone technique," Bol. Soc. Esp. Ceram. 47, 352-357 (2008).

[19] D. Sola, D. Conejos, J. M. De Mendivil, L.O. SanMartín, G. Lifante, and J.I. Peña, Directional solidification, thermo-mechanical and optical properties of $\left(\mathrm{Mg}_{\mathrm{x}} \mathrm{Ca}_{1-}\right.$ х) ${ }_{3} \mathrm{Al}_{2} \mathrm{Si}_{3} \mathrm{O}_{12}$ glasses doped with $\mathrm{Nd}^{3+}$ ions, Opt. Express 20 (2015) 26356-26358.

[20] F.L. Kennard, R.C. Bradt and V.S. Stubican, Directional Solidification of the $\mathrm{ZrO}_{2}-$ MgO Eutectic, J. Am. Ceram. Soc. 57 (1974) 428-431.

[21] V.M. Orera, R.I. Merino, J.A. Pardo, A. Larrea, J.I. Peña, C. González, P. Poza, J.Y. Pastor and J. LLorca, Microstructure and physical properties of some oxide eutectic composites processed by directional solidification, Acta Mater. 48 (2000) 4683-4689.

[22] J. LLorca, J.Y. Pastor, P. Poza, J.I. Peña, I. de Francisco, A. Larrea, V.M. Orera, Influence of the $\mathrm{Y}_{2} \mathrm{O}_{3}$ content and temperature on the mechanical properties of melt-grown $\mathrm{Al}_{2} \mathrm{O}_{3}-\mathrm{ZrO}_{2}$ eutectics, J. Am. Ceram. Soc. 87 (2004) 633-639.

[23] K.A. Jackson and J. D. Hunt, Lamellar and Rod Eutectic Growth, Trans. Metal. Soc. AIME 236 (1966) 1129-1142.

[24] J. Echigoya, Structure of interface in directionally solidified oxide eutectic systems, J. Eur. Ceram. Soc. 25 (2005) 1381-1387.

[25] A. Orera, Private communication. 
[26] K. Bundschuh and M. Schütze, Materials for temperatures above $1500{ }^{\circ} \mathrm{C}$ in oxidizing atmospheres Part I: Basic considerations on materials selection, Materials and Corrosion 52 (2001) 204-212.

[27] I. Barin, Thermochemical Data of Pure Substances, third ed.,VCH, New York, 1995.

[28] A. Jouini, A. Yoshikawa, Y. Guyot, A. Brenier, T. Fukuda, G. Boulon, Potential candidate for new tunable solid-state laser between 1 and $2 \mu \mathrm{m}: \mathrm{Ni}^{2+}$-doped $\mathrm{MgAl}_{2} \mathrm{O}_{4}$ spinel grown by the micro-pulling-down method, Opt. Mat. 30 (2007) 4749

[29] D. Cáceres, I. Vergara, R. González, Y. Chen. Hardness and elastic modulus from nanoindentations in nominally pure and doped $\mathrm{MgO}$ single crystals. Phil. Mag. A 82, (2002) 1159-1171.

[30] M. V. Swain, R. C. Garvie, R. H. J. Hannink. Influence of thermal decomposition on the mechanical properties of magnesia-stabilized cubic zirconia. J. Am. Ceram. Soc. 66 358-362 (1983).

[31] G.D. Quinn, R.C. Bradt, On the Vickers indentation fracture toughness test, J. Am Ceram. Soc. 90 (2007) 673-680.

[32] K. Niihara, R. Morena, D.P.H. Hasselman, Evaluation of $\mathrm{K}_{\mathrm{IC}}$ of brittle solids by the indentation method with low crack-to-indent ratios, J. Mater. Sci. Lett. 1 (1982) $13-16$.

[33] G.R. Anstis, P. Chantikul, B.R. Lawn, D.B. Marshall, A critical evaluation of indentation techniques for measuring fracture toughness: I direct crack measurements, J. Am. Ceram. Soc. 64 (1981) 533-538. 
[34] N. Mironova-Ulmane, M.G. Brik and I. Sildos, Crystal field calculations of energy levels of the $\mathrm{Ni}^{2+}$ ions in $\mathrm{MgO}$. J. of Luminescence 135 (2013) 74-78.

[35] B. Henderson and G.F. Imbush. "Optical Spectroscopy of Inorganic Solids". Monographs on the Physics and Chemistry of Materials, Oxford University Press, New York, 1989.

[36] M.V. Iverson, J.C. Windsheif and W.A. Sibley, Optical Parameters for the $\mathrm{MgO}: \mathrm{Ni}^{2+}$ laser system, Appl. Phys. Letters 36 (1980) 183-184.

[37] P.B. Oliete, A. Orera, M.L. Sanjuán, R.I. Merino, Selective thermal emission of directionally solidified $\mathrm{Al}_{2} \mathrm{O}_{3} / \mathrm{Y}_{3-\mathrm{x}} \mathrm{Er}_{\mathrm{x}} \mathrm{Al}_{5} \mathrm{O}_{12}$ eutectics: Influence of the microstructure, temperature and erbium content, Sol. Energy Mater. Sol. Cells 174 (2018) 460-468.

[38] K.D. Becker, F. Rau, A high-temperature study of defect-induced optical absorption in nickel oxide, $\mathrm{Ni}_{1-\delta} \mathrm{O}$, Ber. Bunsenges. Phys. Chem. 96 (1992) $1017-$ 1027.

[39] L. G. Ferguson and L. M Fraas, Energy-band-matched infrared emitter for use with low bandgap thermophotovoltaic cells, United States Patent 5,865,906 (Issued Feb. 2 1999)

[40] L. Dombrovsky, B. Rousseau, P. Echegut, J. H. Randrianalisoa, D. Baillis. High temperature infrared properties of YSZ electrolyte ceramics for SOFCs: experimental determination and theoretical modelling, J. Am. Ceram. Soc. 94 (2011) 4310-4316. 
[41] S. M. Avdoshenko, A. Strachan, High temperature emissivity of silica, zirconia and samaria from ab initio simulations: role of defects and disorder. Modelling Simul. Mater. Sci. Eng. 22 (2014) 075004. 